\title{
Damage-control laparoscopic partial cholecystectomy with an endoscopic linear stapler
}

Beyza Özçınar, Ecem Memişoğlu, Ali Fuat Kaan Gök, Orhan Ağcaoğlu, Fatih Yanar, Mehmet Illhan, Hakan Teoman Yanar, Kayıhan Günay

ABSTRACT
$\begin{aligned} & \text { Objective: Several damage-control procedures have been described in the literature in case of severe Calot's triangle } \\ & \text { inflammation and fibrosis. In this report, we describe patients who underwent laparoscopic partial cholecystectomy } \\ & \text { using an endoscopic linear stapler. } \\ & \text { Materials and Methods: Five patients with acute cholecystitis underwent laparoscopic partial cholecystectomy in our } \\ & \text { clinic between January - December 2011. All patients had severe fibrosis and inflammation of Calot's triangle. The } \\ & \text { anterior and posterior walls of the gallbladder were totally resected if possible. The gallbladder was transected at its } \\ & \text { neck or Hartmann's pouch, leaving a remnant gallbladder pouch behind. } \\ & \text { Results: Five patients had laparoscopic partial cholecystectomy with an endoscopic linear stapler. The main symptom } \\ & \text { of all patients on admission to the emergency room was abdominal pain. The mean time for the surgical procedure } \\ & \text { was } 140 \text { minutes (range, 120-180 minutes). Inflammation and fibrosis of Calot's triangle was detected in all patients } \\ & \text { during surgery and a phlegmonous gallbladder was detected in one patient. Surgical drains were used in all patients } \\ & \text { and no biliary leakage was detected. Remnant common bile duct calculi were detected in one patient and this patient } \\ & \text { underwent endoscopic retrograde cholangiopancreatography one month after surgery. } \\ & \text { Conclusions: When a reliable view of Calot's triangle cannot be obtained due to severe inflammation and fibrosis dur- } \\ & \text { ing laparoscopy, laparoscopic partial cholecystectomy seems to be a safe and feasible alternative to open surgery with } \\ & \text { an acceptable morbidity rate. } \\ & \text { Keywords: Acute cholecystitis, damage control surgery, endoscopic linear stapler, laparoscopy, partial cholecystectomy }\end{aligned}$

Cite this paper as: Özçınar B, Memişoğlu E, Gök AFK, Ağcaoğlu 0, Yanar F, Illhan M, et al. Damagecontrol laparoscopic partial cholecystectomy with an endoscopic linear stapler. Turk J Surg 2017; 33(1):37-39.

Department of General Surgery, İstanbul University İstanbul School of Medicine, İstanbul, Turkey

Address for Correspondence Beyza Özçınar e-mail:drbeyza@hotmail.com

Received: 24.07.2015

Accepted: 26.10 .2015

@C Copyright 2017 by Turkish Surgical Association

Available online at www.turkjsurg.com

\section{INTRODUCTION}

Laparoscopic management of gallstones and acute cholecystitis has become standard of care in current practice. Open cholecystectomy is usually performed in patients with severe inflammation where there is a requirement to convert to open surgery or in gallbladder malignancy.

Due to safety concerns, conversion to open surgery is advocated to prevent injury to the bile duct or major blood vessels if biliary tract anatomy cannot be clearly identified. In case of severe Calot's triangle inflammation and fibrosis, the rate of injury to the biliary tract and portal structures increase. Several damage-control procedures have been described in the literature for such circumstances (1-5).

In the current era of laparoscopy and high definition (HD) systems, conversion to open procedure for these cases is not always required. One of the damage-control procedures to be used is laparoscopic partial cholecystectomy (LPC), and various techniques have been described for LPC (6-8).

In this report, we describe patients who underwent LPC in our clinic with an endoscopic linear stapler.

\section{MATERIAL AND METHODS}

Five patients who presented to İstanbul University Istanbul School of Medicine General Surgery Department, Trauma and Emergency Medicine Unit with acute cholecystitis between January - December 2011 were included in the study. The demographic and clinical data of these patients were collected retrospectively. Informed consents were given from the patients.

All patients underwent surgery for acute cholecystitis and/or biliary pancreatitis. Laparoscopic procedures were performed in all patients with four standard trocars and HD systems (Karl Storz; GmbH \& Co. KG, Tuttlingen, Germany). All patients had fibrosis and severe inflammation of Calot's triangle.

A laparoscopic partial cholecystectomy was performed in all patients. The anterior and posterior walls of the gallbladder were totally resected if possible. The gallbladder was transected at its neck or Hartmann's pouch, leaving a remnant gallbladder pouch behind. The gallbladder pouch was closed using a linear 
endoscopic stapler (Endopath Ets Articulating Linear Cutters; Johnson \& Johnson, New Jersey, USA). Staple line lengths and cut line were selected according to gallbladder wall thickness (35 mm [cut line $32 \mathrm{~mm}$ ], $45 \mathrm{~mm}$ [cut line $41 \mathrm{~mm}$ ], and $60 \mathrm{~mm}$ [cut line $56 \mathrm{~mm}$ ]). The pouch was cleared of remnant calculi before closing with the endoscopic stapler to minimize complications. The remnant mucosa was coagulated to reduce the secretion from mucosa and surgical drains were routinely used.

\section{RESULTS}

During a one-year period in Trauma and Emergency Medicine Unit, 200 patients underwent laparoscopic or open cholecystectomy for acute cholecystitis or biliary pancreatitis. Of the 200 patients, five underwent laparoscopic partial cholecystectomy with an endoscopic linear stapler. One (20\%) of these patients was female and four (80\%) were male. The mean age of patients was 49 years (range, 31-61 years). The main symptom of all patients on admission to the emergency room was abdominal pain. All patients had acute cholecystitis at admission; four patients also had acute biliary pancreatitis, and two had obstructive jaundice.

Antibiotic treatment was started on the day of admission in all patients. Two patients with obstructive jaundice underwent preoperative endoscopic retrograde cholangiopancreatography (ERCP). Papillotomy and stone extraction from the common bile duct was performed in both patients.

One patient underwent surgery in the acute phase of cholecystitis, 3 days after the onset of symptoms, two patients after recovering from the signs and symptoms of acute biliary pancreatitis at day 9 and 10. Two patients underwent surgery at later periods, one and two months after the onset of symptoms. The mean surgical procedure time was 140 minutes (range, 120-180 minutes).

Inflammation and fibrosis of Calot's triangle was detected in all patients during surgery and phlegmonous gallbladder was detected in one. Surgical drains were placed in all patients. The mean drainage time was 4.8 days (range, 1-13 days) and no biliary leakage was detected after surgery. The mean hospital length of stay was 7.4 days (range, 3-13 days). None of the patients had bile duct injury, symptoms of remnant gallstones, and/or stump cholecystitis after surgery.

None of the patients required reoperation for any reason. Remnant common bile duct calculi were detected in one patient who underwent ERCP one month later. Papillotomy and stone extraction from the common bile duct was performed in this patient. None of the patients had wound infections, subhepatic or subphrenic abscesses or hematoma after surgery. There was no in-hospital mortality. The median follow-up time was 15 months (range, 12-20 months). During the follow-up period, one patient had recurrent cholecystitis of the remnant gallbladder that was conservatively treated.

\section{DISCUSSION}

When severe inflammation and fibrosis of Calot's triangle is observed in cases of acute cholecystitis, conversion to open surgery or partial cholecystectomy (PC) is recommended to preserve the biliary tract and associated arterial structures. Partial cholecystectomy has been described in the literature since the beginning of the 20th century $(1,9,10)$. The definition of partial cholecystectomy requires that some portion of the gallbladder is left in continuity with the cystic duct and not resected (11).
Partial cholecystectomy can be performed laparoscopically or as an open procedure depending on the surgeon's experience. Experienced surgeons may feel comfortable performing damage-control procedures laparoscopically (12).

In case of a difficult gallbladder, a change in surgical strategy rather than conversion to an open approach seems more feasible. In this situation, antegrade cholecystectomy or LPC can be performed (13). Partial cholecystectomy is not surgical failure. More precisely, it is wise for a surgeon to perform a partial cholecystectomy in difficult cases rather than causing disastrous complications. Surgical skill and experience combined with good quality microscopes with HD systems play the most important role in choosing damage-control strategies (laparoscopic or open). ERCP is the best rescue method for post PC complications.

Many LPC techniques have been described in the literature. Some authors close the remnant gallbladder whereas some leave them open. Many surgeons perform only anterior wall excision and leave the posterior wall, and may or may not coagulate the remnant gallbladder mucosa. All of these techniques can be used with acceptable success rates. The choice depends on surgeon preference and the features of the case. However, the main aims in all cases should be to resect the maximum amount of gallbladder wall without major complications, remove all stones from the remnant gallbladder, and coagulate the remnant mucosa to reduce postoperative secretion. After LPC, drainage systems are used in some patients but not all. In the current report, we resected the anterior and posterior walls of the gallbladder if possible, and a minimal remnant of the gallbladder at the level of Hartmann's pouch was left in situ, remnant mucosa was coagulated, gallstones were aspirated, the remaining gallbladder pouch was closed using a linear endoscopic stapler, and surgical drainage was routinely used.

The major morbidities of LPC are bile leakage, remnant symptomatic gallstones, remnant cholecystitis, subphrenic or subhepatic abscess due to continuous drainage from the remnant mucosa, and need for reoperation. In our review of PC literature, the most common complication was bile leakage (11\%), while the rate of recurrence of symptomatic gallstones was about $2 \%(6,14)$. In the present report none of the patients developed bile leakage, and there was only one case of recurrent remnant gallstones. During the follow-up period, one patient developed remnant cholecystitis, which was conservatively treated. No intraabdominal abscesses were detected. In the literature, the rate of remnant common bile duct stones after laparoscopic cholecystectomy ranges between $0.5-12 \%$ (15-17). Although postoperative remnant bile duct stones and postoperative ERCP after PC are not uncommon, it was detected in about $0-20 \%$ of cases. In our current report, ERCP was required postoperatively in only one patient (20\%). This rate seems to be high; however, the current report contains a low total number of cases, which is the most important limitation of our case series.

\section{CONCLUSION}

In conclusion, when a reliable view of Calot's triangle cannot be obtained due to severe inflammation and fibrosis during laparoscopy, LPC seems to be a safe and feasible alternative to open surgery with an acceptable morbidity rate. Moreover, closure of the remnant gallbladder with an endoscopic linear stapler is also a fast, safe, and effective method as compared to hand suturing, and did not result in bile leakage in our series. 
Informed Consent: Written informed consent was obtained from patients who participated in this study.

Peer-review: Externally peer-reviewed.

Author Contributions: Concept - B.Ö.; Design - E.M., O.A.; Supervision - H.T.Y., K.G.; Resource - H.T.Y.; Materials - A.F.K.G., M.I., F.Y.; Data Collection and/or Processing - B.Ö., E.M., Analysis and/or Interpretation - O.A.; Literature Search - E.M., O.A.; Writing Manuscript - E.M., B.Ö.; Critical Reviews - B.Ö., H.T.Y., K.G.

Conflict of Interest: No conflict of interest was declared by the authors.

Financial Disclosure: The authors declared that this study has received no financial support.

\section{REFERENCES}

1. Bornman PC, Terblanche J. Subtotal cholecystectomy: for the difficult gallbladder in portal hypertension and cholecystitis. Surgery 1985; 98: 1-6.

2. Chowbey PK, Sharma A, Khullar R, Mann V, Baijal M, Vasthistha A. Laparoscopic subtotal cholecystectomy: a review of 56 procedures. J Laparoendosc Adv Surg Tech A 2000; 10: 31-34. [CrossRef]

3. Subramaniasivam N, Ananthakrishan N, Kate V, Smile R, Jaqdish $\mathrm{S}$, Srinivasan K. Partial cholecystectomy in elective and emergency gall bladder surgery in the high risk patients--a viable and safe option in the era of laparoscopic surgery. Trop Gastroenterol 1996; 17: 49-52.

4. Palanivelu C, Rajan PS, Jani K, Shetty AR, Sendhilkumar K, Senthilnathan $\mathrm{P}$, et al. Laparoscopic cholecystectomy in cirrhotic patients: the role of subtotal cholecystectomy and its variants. J Am Coll Surg 2006; 203: 145-151. [CrossRef]

5. Lee J, Miller P, Kermani R, Dao H, O'Donnell K. Gallbladder damage control: compromised procedure for compromised patients. Surg Endosc 2012; 26: 2779-2783. [CrossRef]

6. Henneman D, da Costa DW, Vrouenraets BC, van Wagensveld BA, Lagarde SM. Laparoscopic partial cholecystectomy for the diffi- cult gallbladder: a systematic review. Surg Endosc 2013; 27: 351358. [CrossRef]

7. Beldi G, Glattli A. Laparscopic sutotal cholecystectomy for severe cholecystitis. Surg Endosc 2003; 17: 1437-1439. [CrossRef]

8. Hubert $C$, Annet $L$, van Beers Be, Gigot F. The inside approach of the gallbladder is an alternative to the classic Calot's triangle dissection for a safe operation in severe cholecystitis. Surg Endosc 2010; 24: 2626-2632. [CrossRef]

9. Stevens BC. Cholecystectomy: Partial Hepatectomy and Pylorectomy: Recovery. Br Med J 1901; 1: 878-879. [CrossRef]

10. Lerner Al. Partial cholecystectomy. Can Med Assoc J 1950; 63: 5456.

11. Sharp CF, Garza ZR, Mangram AJ, Dunn EL. Partial cholecystecto$m y$ in the setting of severe inflammation is an acceptable consideration with few long term sequele. Am Surg 2009; 75: 249-252.

12. Kulen F, Tihan D, Duman U, Bayam E, Zaim G. Laparoscopic Partial Cholecystectomy: A safe and effective alternative surgical technique in "difficult cholecystectomies". Ulus Cer Derg 2016; 32: 185-190. [CrossRef]

13. Booij KA, de Reuver PR, van Delden OM, Gouma DJ. Conversion has to be learned: bile duct injury following conversion to open cholecystectomy. Ned Tijdschr Geneeskd 2009; 153: A296.

14. Karaköse O, Sabuncuoğlu MZ, Benzin MF, Çelik G, Bülbül M, Pulat $\mathrm{H}$. Development of acute cholecystitis following laparoscopic partial cholecystectomy. Ulus Cer Derg 2015. DOI: 10.5152/ UCD.2015.3060 [Epub ahead of print]. [CrossRef]

15. Anwar S, Rahim R, Agwunobi A, Bancewicz J. The role of ERCP in management of retained bile duct stones after laparoscopic cholecystectomy. J New Zeland Med Ass 2004; 117: U1102.

16. Prat F, Pelletier G, Ponchon T, Fritsch J, Meduri B, Boyer J, et al. What role canendoscopy play in the management of biliary complications after laparoscopiccholecystectomy? Endoscopy 1997; 29: 341-348. [CrossRef]

17. Frazee RC, Roberts J, Symmonds R, Hendricks JC, Snyder S, Smith $\mathrm{R}$, et al. Combined laparoscopic and endoscopic management of cholelithiasis and choledocholithiasis. Am J Surg 1993; 166: 702-706.[CrossRef] 